\title{
Management of unstable Dorsolumbar spine injuries with transpedicular rod and screw fixation
}

\author{
Dr.Nitin Kansal ${ }^{1}$, Dr.Atul Agrawal ${ }^{2}$ \\ ${ }^{I}$ (Assistant professor,Department of Orthopaedics, Himalayan Insitute of Medical Sciences, Dehradun,India) \\ ${ }_{2}^{2}$ (Assistant professor,Department of Orthopaedics, Himalayan Insitute of Medical Sciences, Dehradun,India)
}

\begin{abstract}
BACKGROUND: DORSOLUMBAR TRAUMA IS THE MOST COMMON CAUSE OF PARAPARESIS OR PARAPLEGIA. OPTIMAL GOALS OF THE MANAGEMENT INCLUDE ESTABLISHMENT OF A PAINLESS, BALANCED AND STABLE SPINAL COLUMN WITH VERTEBRAL FUSION. MATERIAL \& METHOD: We REVIEWED VARIOUS TYPeS OF FRACTURES OF DORSOLUMBAR SPINE, THEIR MANAGEMENT AND OUTCOME IN A PROSPECTIVE STUDY OF 32 CASES OF DORSOLUMBAR TRAUMA MANAGED SURGICALly AT OUR CENTRE (JUNE 2008 - OCTOBER 2010). ALL PATIENTS UNDERWENT COMPLETE NEUROLOGICAL EXAMINATION, CT AND MR IMAGING OF THE SPINE. STUDY Design \& SetTings: Prospective observational STUdy in A TERTIARY CARE CENTRE FROM 2008-2010. RESULTS: MOST COMMON MODE OF INJURY WAS FALL FROM HEIGHT (66\%). MAJORITY OF THE PATIENTS BELONGED TO FRANKEL GRADE A (66\%). ALL PATIENTS WERE OPERATED USING POSTERIOR APPROACH. THERE WAS NO DETERIORATION IN NEUROLOGICAL STATUS IN ANY OF THE PATIENTS WHILE EIGHT PATIENTS HAD IMPROVEMENT. AVERAGE LOCAL KYPHOTIC ANGLE PREOPERATIVELY WAS 23 DEGREE .AVERAGE LOCAL KYPHOSIS ANGLE POSTOPERATIVELY WAS 5.8 DEGREE. AVERAGE LOCAL KYPHOSIS ANGLE AT FINAL FOLLOW UP WAS 8 DEGREE RANGE FROM 0-13 DEGREE WITH LOSS OF KYPHOSIS ANGLE WAS 2.2 DEGREE STATISTICS:

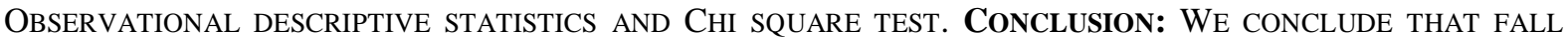
FROM HEIGHT IS THE MOST COMMON CAUSE OF DORSOLUMBAR FRACTURE WITH MAJORITY AFFECTED BELONGING TO YOUNG POPULATION AND HAD SIGNIFICANT DEFICITS, THUS CAUSING SIGNIFICANT BURDEN ON THE SOCIETY. PROMPT SURGICAL MANAGEMENT IS SAFE AND HELPS IN EARLY MOBILIZATION AND REHABILITATION, THUS FACILIT ATING POSSIBLE NEUROLOGICAL RECOVERY AND ACHIEVING AN IMPROVED QUALITY OF LIFE.
\end{abstract}

Keywords - Dorsolumbar fracture, Frenkels Score, Paraplegia, Rehabilitation, Transpedicular fixation.

\section{INTRODUCTION}

Trauma to the thoracic and lumbar vertebra is one of the most common cause of traumatic paraparesis or paraplegia[1,2]. These can occur with or without bowel bladder involvement. Dorsolumbar fractures often cause a neurologic deficit and present a significant economic burden to the family and society. Accepted methods of treatment of dorsolumbar burst fractures include conservative therapy, posterior reduction and instrumentation, and anterior decompression and instrumentation. Early mobilization and rehabilitation is the most important aim of the management [1,3]. Majority of the dorsolumbar fractures are unstable. Optimal goals of the management include establishment of a painless, balanced and stable spinal column with fusion of least number of vertebra ${ }^{4}$. The management of dorsolumbar fractures has been the subject of much controversy. There exist different criteria for the choice of the management based on the severity of kyphotic deformity, canal compromise, vertebral height loss, and neurologic Status [1,4,5]. To our knowledge, none of the existing criteria for the treatment of dorsolumbar burst fractures is generally accepted. In this study we review various types of fractures of dorsolumbar spine, their management and outcome.

\section{MATERIAL \& METHOD}

All surgically treated dorsolumbar fractures between October 2008 and August 2010 were reviewed prospectively at Government medical college, Surat. All patients had undergone complete neurological examination, roentegraphy and magnetic resonance imaging. Clinically Patients were graded using Frankel classification of neurological deficits pre- and postoperatively as follows:

A. Absent motor and sensory function

B. Sensation present, motor function absent

C. Sensation present, motor function active but not useful (grade 2-3/5)

D. Sensation present, motor function active and useful (grade 4/5)

E. Normal motor and sensory function.

Preoperative plain radio- graphs with sagittal and axial computed tomography (CT) scans were reviewed regarding three separate characteristics of the fracture site. 
a). The amount of vertebral body actually comminuted by the injury, as best seen in sagittal CT, or lateral plain X-ray.

b) The apposition of the fracture fragments, as best seen on axial CT cuts through the fracture site.

c) The fractures were categorized to 5 main groups according to mode of injury and pathomorphological uniformity[6]- 1. Compression Fracture 2. Burst Fractures 3. Flexion Distraction Injuries 4. Fracture Dislocations 5. Spondyloptosis

All patients were operated and fixation with or without fusion was done. Post operatively patients underwent either X-ray or CT and were examined for construct placement, spinal canal decompression and kyphosis correction (Fig. 1, 2). Local kyphosis angle was measured by Kobb method i.e. the angle between two lines,the first is perpendicular to the superior end plate of the vertebra above and second is inferior end plate of the vertebra below. All of them were mobilized using dorsolumbar brace from the second postoperative day. Regular physiotherapy was done in all patients after the surgery Observational descriptive statistical analysis was done using SPSS 19.0 for windows.

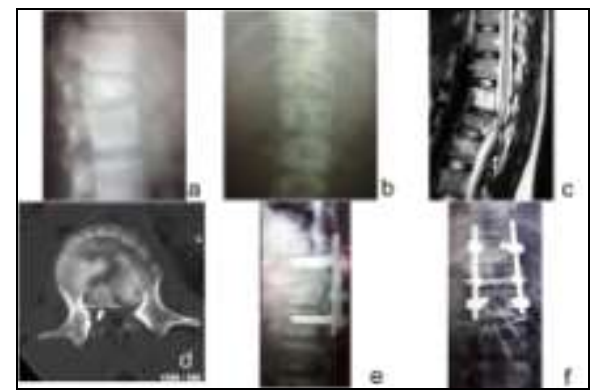

Fig-1 40 year old male with fall from height with burst fracture L2 vertebra. a,b- preoperative xrays c-mri showing cord compression with cord changes $d$ - ct scan showing burst fracture with retropulsed fragment posteriorly into the canal e,f- post operative images with vertebral height well maintained and stable fixation.

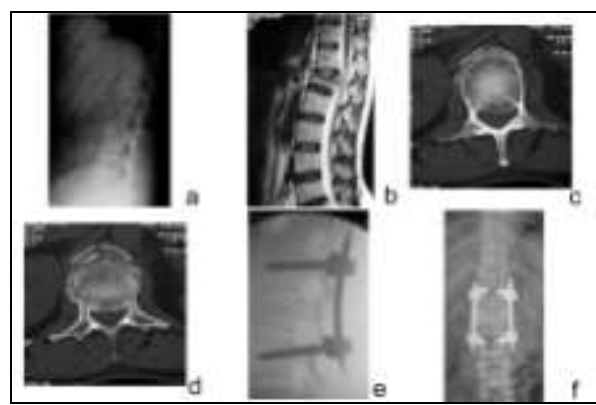

Fig-2 25 year old female with wedge compression fracture L1 vertebra. a- preoperative xray b-mri showing cord compression without any cord changes c,d- ct scan showing compression fracture with some canal compromise. e,f- post operative images with vertebral height well maintained and stable fixation.

\section{RESULTS}

We analyzed all surgically treated dorsolumbar fractures treated by orthopaedics department of this tertiary care centre from October 2008 to August 2010.

\subsection{Epidemiology}

Our patients ranged from $18 \mathrm{yrs}$ to $50 \mathrm{yrs}$ (Mean \pm SD 33.0 \pm 12.15 ) with 24 males and 8 females. Most importantly majority of them belonged to age group of 20-39 (65\%). Most common mode of injury was fall from height $(66 \%)$. Road traffic accidents accounted for nine out of which almost all were due to running over by the vehicle or due to high-speed acceleration deceleration, injury .One patient had fracture due to gunshot injury.

3.2 Clinical Profile

Majority of our patient (66\%) belonged to Frankel grade A, i.e., complete motor and sensory loss below the injury. Only $20 \%$ of the patients had some useful motor sensory function. Twenty-two patients (69\%) had bowel bladder involvement. Majority of the patients (87.5\%) had some neurological deficit. Ten patients (31\%) had associated systemic injuries (5 out of 12 in high velocity injury compared to 5 out of 20 low velocity injuries).

\subsection{Radiology}

Most common vertebra involved was L1 vertebral body (12 patients). Common type of fractures were compression and burst fractures both accounting for 12 each (Table 1). On MR imaging 9 patients (28\%) 
showed complete cord transection. Another 14 (44\%) showed cord signal changes with nine (28\%) showing normal cord.

Table 1

Fracture Pattern in Dorsolumbar Spinal Injuries

\begin{tabular}{|c|c|}
\hline Compression Fracture & $12(37.5 \%)$ \\
\hline Burst Fractures & $12(37.5 \%)$ \\
\hline Flexion Distraction Injuries & $3(9.5 \%)$ \\
\hline Fracture Dislocations & $5(15.5 \%)$ \\
\hline Spondyloptosis & 0 \\
\hline
\end{tabular}

3.4 Surgical Management

Mean duration from injury to surgery was $11 \pm 5.6$ days. All of them were approached posteriorly. Short segment fixation was done in 20 patients where as in 12 patients long segment fixation was done. Autologous bone graft was used in 15 patients for fusion.

3.5 Postoperative Complications

Most common complication was chest infection (14\%). Wound infection was present in 2 patients (6\%). One patient developed sepsis with multiorgan dysfunction syndrome. Two patients had construct failure with screw pullout and had to be operated again.

3.6 Outcome

Outcome was measured at 4-month follow up or at last follow up visit. Mean follow up was 6.2 months with range of 4 to 10 months. Eleven patients had a follow up of 6 months in our study. Overall, eight patients had neurological improvement while four of them had significant motor improvement. Out of 25 patients in Frankel A- C, only five patients improved neurologically, while 3 in Frankel grade D showed improvement and all 4 patients in Frankel type E were neurologically same. However, there was no statistical significance for Frankel grade in predicting the improvement of the patient except in grade A patients (Table 2). None of the patient had neurological deterioration. The surprising finding was that one patient of Frankel grade A also showed improvement in his neurological status.

Table 2

Correlation of prognosis with Frankel grade on admission

\begin{tabular}{|c|c|c|c|}
\hline Frankel Grade & Improved & Same & $\boldsymbol{P}$ value \\
\hline $\mathbf{A}(\mathbf{n}=\mathbf{2 1})$ & 1 & 20 & $\mathbf{0 . 0 0 1}$ \\
\hline $\mathbf{B} / \mathbf{C}(\mathbf{n}=\mathbf{4})$ & 4 & 0 & 0.208 \\
\hline $\mathbf{D}(\mathbf{n}=\mathbf{3})$ & 3 & 0 & 0.464 \\
\hline $\mathbf{E}(\mathbf{n}=\mathbf{4})$ & 0 & 4 & 0.208 \\
\hline
\end{tabular}

Five out of $11(45 \%)$ patients who were operated within 7 days of injury showed neurological improvement compared to three out of 21 patients who were operated after 7 days of injury (Table 3). This figures show that early surgery is beneficial in neurological recovery of these patients. However, the P value was not statistically significant $(\mathrm{p}=0.08)$. There was a statistically significant correlation between the cord change on MRI and the neurological recovery at final follow up. Our study also showed that there was no correlation of outcome with preoperative methyl prednisolone, other systemic injury or hypotension (Table 4). Majority of the patients (22) were still voiding through urinary catheter. Bedsore was present in six (18\%) patients.

Table 3

Correlation with the timing of surgery

\begin{tabular}{|c|c|c|c|}
\hline Duration before surgery & $<7$ days $(\mathbf{N}=11)$ & \multirow{2}{*}{ P value } \\
\cline { 1 - 3 } Improvement & 5 & 3 & \multirow{2}{*}{0.08} \\
\hline Same & 6 & 18 & \\
\hline
\end{tabular}

Table 4

Other prognostic factors 


\begin{tabular}{|c|c|c|c|}
\hline & Improved & Same & P value \\
\hline Age & 1 & 3 & \\
$<20(\mathrm{n}=4)$ & 5 & 16 & 0.894 \\
$20-40(\mathrm{n}=21)$ & 2 & 5 & \\
$>40(\mathrm{n}=7)$ & 2 & 21 & $\mathbf{0 . 0 0 2}$ \\
\hline $\begin{array}{c}\text { MRI } \\
\text { Cord change }(\mathrm{n}=23)\end{array}$ & 6 & 3 & \\
\hline No change $(\mathrm{n}=9)$ & 3 & 9 & 1.0 \\
\hline Mechanism of injury & 5 & 15 & \\
High velocity $(\mathrm{n}=12)$ & 1 & 3 & 0.575 \\
\hline Low velocity(n=20) & 2 & 8 & 0.235 \\
\hline Hypotension(n=4) & 2 & & \\
\hline MethylPrednisolone (n=10) & 2 &
\end{tabular}

3.7 Local kyphosis angle as measured by Kobb's method

Average local kyphotic angle preoperatively was $23^{\circ}$ with a range from $18-30^{\circ}$. Average local kyphotic angle postoperatively was $5.8^{0}$ with a range from $0-8^{0}$. Average local kyphosis angle at final follow up was $8^{0}$ with a range from $0-13^{0}$. The loss of kyphosis angle from immediate post operative to final follow up was $2.2^{0}$.

\section{DISCUSSION}

Dorsolumbar spine fractures account for the most common cause of traumatic paraplegia. Most of the affected belong to the productive age group, thus having a major economic burden on the society. The aim of treatment is restoration of function of the patient by creating a healing environment to allow a stable pain free spinal column, with the minimal risk to the patient $[7,8,9]$. The management of fractures in the thoracolumbar region is a controversial subject. Disadvantages of conservative treatment include deterioration in neurological status in $17 \%$ of the patients, progressive kyphotic deformity in $20 \%$, persistent backache, decubitus ulcer and deep venous thrombosis. Most of these complications can be avoided by early mobilization and decreased hospital stay by early surgery $[7,9,10]$. In our series, majority had severe neurological deficits, with the mean pre op Frankel score being $1.93 \pm 1.4$. This was very low compared to all the studies conducted previously as shown in the Table 5. This could explain the lower percentage of neurological improvement compared to others in our study. As shown with other studies pre operative Frankel score was the single most important factor deciding the neurological outcome $[5,6]$. Even though Statistically insignificant, greater fraction of patients operated within 7 days showed improvement compared to those who where operated after 7 days. Our study showed that no cord changes on MRI at the time of injury had good neurological recovery. The study showed that almost all patients with incomplete cord injury improved with time. Only factor which was significant in deciding the outcome was pre operative frankel score, with almost all patients who had preoperative frankel of $\mathrm{C}, \mathrm{D}$ or E showing improvement as shown by other studies as well $[6,7]$. Even in complete cord injury the incidence of complication due to immobilization of patients were reduced dramatically with improved quality of life. In our study average loss of kyphosis angle was 2.2 degree. While in study by Daniaux et al [12] the loss was 3 degree. And in study by El zeher Hassan et al [13] the average loss of kyphotic angle was 4.2 degree. We suggest that for better correction and maintenance of kyphotic angle global fixation along with fusion should be taken into consideration. Thus early surgery can help in rehabilitation and mobilization of patients thus preventing the complications such as decubitus ulcers, chest infection deep venous thrombosis etc. this also makes patients independent on others for their daily activities.

Table 5

Management of dorsolumbar spine trauma in the literature

\begin{tabular}{|l|c|c|c|c|}
\hline \multicolumn{1}{|c|}{ Study } & (n) & Mean frankel & Improved & Worse \\
\hline Patrick w. Hitchon etal(8) & 63 & $3.7 \pm 1.1$ & 23 & 2 \\
\hline Mohammad F. Butt et al (11) & 50 & $2.2 \pm 1.2$ & 24 & 0 \\
\hline Present study 2010 & 32 & $1.9 \pm 1.4$ & 8 & 0 \\
\hline
\end{tabular}

\section{CONCLUSION}

Fall from height is the most common cause of dorsolumbar fractures with majority affected belonging to young population and presenting with significant deficits, thus causing significant burden on the society. Surgical management is safe and helps in early mobilization and rehabilitation, thus facilitating possible neurological recovery. Long-term follow up of patients are still awaited. 


\section{REFERENCES}

[1] Hassan Dashti, Haw Chou Lee, Eldin E Karaikovic, RobertW. Gaines Jr. Decision making in dorsolumbar fractures. Neurology India 53, 2005, 4.

[2] Denis F. Spinal Instability As Defined by the Three-Column Spine Concept in Acute Spinal Trauma. Clin Orthop 189, 1984, 6576.

[3] Denis F. The Three Column Spine and Its Significance in the Classification of Acute Thoracolumbar Spinal Injuries. Spine 8, $1983,817-31$.

[4] Panjabi MM, Oxland TR, Kifune M, Arand M, Wen L, Chen A. Validity of the Three-Column Theory of Thoracolumbar Fractures-A Biomechanic Investigation. Spine 20, 1995, 1122-7.

[5] Alvine GF, Swain JM, Asher MA, Burton DC. Treatment of thoracolumbar burst fractures with variable screw placement or Isolated instrumentation and arthrodesis: Case series and literature review. J Spinal Disord Tech 17, 2004, 251-64.

[6] Gertzbein SD. Spine update. Classification of thoracic and lumbar fractures. Spine 19, 1994, 626-8.

[7] Lemons VR, Wagner FC, Montesano PX. Management of thoracolumbar fractures with accompanying neurological injury. Neurosurgery 30, 1992, 667-71.

[8] Hitchon PW, Torner JC, Haddad SF, Follett KA. Management options in thoracolumbar burst fractures. Surg Neurol 49, 1998, 619-27.

[9] Rechtine GR II, Cahill D, Chrin AM. Treatment of thoracolumbar trauma: comparison of complications of operative versus nonoperative treatment. J Spinal Disord 12, 1999, 406-9.

[10] Hitchon PW, Torner JC. Recumbency in thoracolumbar fractures. Neurosurg Clin N Am 8, 1997, $509-17$.

[11] Mohammad F. Butt, Munir Farooq, Bashir Mir, et al. Management of unstable thoracolumbar spinal injuries by posterior short segment spinal fixation. International Orthopaedics 31,2007, 259-64.

[12] Daniaux H, Seykora P, Genelin A, Lang T, and Kathrein A. Application of posterior plating and modifications in thoracolumbar spine injuries- Indication, techniques and results. Spine 16, 1991, S 125.

[13] El Zaher Hasan El Zaher, Salah Abdel Gawad Abou Seif, Magdy Gamal, Youssef. Evaluation of transpedicular fixation in treating dorsolumbar injuries. Pan Arab J Orth Trauma 4(2), 2000, 103-9. 